\title{
Toward a joint growing of research and teaching in university based on information technology
}

\author{
Yanfei Liu ${ }^{\# 1}$, Zhiqiang Tian ${ }^{* 2}$, Yuzhou Liu ${ }^{* * 3}$, Junsong $\mathrm{Li}^{\# 4}$, Feng Fu ${ }^{\# 5}$ \\ ${ }^{*}$ Department of Computer Science \& Technology, Zhejiang Sci-Tech University \\ No. 928, 2nd Avenue, Xiasha Higher Education Zone, Hangzhou 310018, CHINA. \\ ${ }^{1}$ yliuezju.edu.cn, ${ }^{4}$ ljscgesina.com, ${ }^{5}$ fufeng@zstu.edu.cn \\ *National Key Laboratory of Human Factors Engineering, Astronaut Research and Training Centre of China \\ No. 26, Beiqing Road, Haidian District, Beijing 100094, China \\ ${ }^{2}$ tianzhiqiang2000@163. com \\ ** Community College of Allegheny County \\ 3 Allegheny Center, Pittsburgh, PA 15212, USA \\ ${ }^{3}$ rcdl@me.com
}

\begin{abstract}
This paper proposes a mutual reinforcement architecture for improving both teaching quality and rising scientific research level based on modern information and communication technology (MICT). Firstly it poses the existing conflict of research and teaching $(R \& T)$ in today's tertiary education system especially in university. Then students' appraisement and professor's evaluation mechanism are constructed along with this framework by adopting mutual constraint relationship between student and teacher. Also a mechanism to prompt teaching based on scientific research is designed. Lots of newly developed methods, equipment and facilities are applied in whole teaching system such as for student's class attendance checking, effectiveness on classroom interaction and so on. We look forward that the application of this platform will be able to ameliorate teaching quality and scientific research level substantially.
\end{abstract}

Keywords - Teaching quality, Scientific research level, Modern information and communication technology, Joint growing, Research to urge teaching.

\section{INTRODUCTION}

As in a welcome meeting which a delegation visits to our college, a dean of Computer Science \& Technology Department complains that he was lost in how can manage effectively teaching and scientific research. If he manages his department according to teaching group, it will not benefit to their scientific research performance. However, if he evaluates his team by scientific research outputs, he finds it cannot separate research from teaching works absolutely. Otherwise when he considers both their colleague's teaching and research works, he find not only it is a very hard work but also there are even more conflicts - what's the quote for respective works. How to solve this conflict of teaching and scientific research in university for professors?

As the research universities are important training base for creative and high-quality professionals; it also takes a major role in development of science, technology and culture as well as an innovative power of sources for social development [1]. Recently, there is a growing trend for development of academic research universities all over the China. The criteria to be ranked as a research university are all based on their scientific research output scores. Many colleges and universities have their own goals to be a research type of university, and faculties are required to be engaged in both teaching and research works [2].

However, it seems that the contradiction between research and teaching in time and space has perturbed faculty for a long time, which is also a realistic and urgent problem that teaching reform and tertiary education are facing. Recently mechanism of research to urge teaching (RUT) emerges in research universities, and its beneficial effects in promotion of R\&T are well documented. This mechanism is series of encouraging policies that teaching revolves around scientific research. The goals of RUT are to change the learning style of students, to encourage them to take initiative, and to develop their enthusiasm and creativity, which require the instructor to adapt their instructional strategies and explore innovative pedagogical approaches. The role of faculty should be changed from knowledge transmitter and instiller to organizer, guider and promoter for students while they're acquiring knowledge [1].

With the rapid development of modern information technology and communication facilities, more and more technical approaches can be applied in daily R\&T work and management. Based on understanding of the relationship between teaching and research functions, strategies to strike a reasonable balance between research and teaching, and modern information and communication technology, this study intends to explore development of joint growing in teaching and research in university, and provide some references for related works.

\section{MICT IN TEACHING AND SCIENTIFIC RESEARCH MANAGEMENT}

New technologies have a powerful influence on all aspects of our society, from daily life to work, from health to business and so on [3]. Obviously, education and especially scientific research in university are not an exception. Many technologies 
have an impact on the way we teach, learn and do research. For example, new mobile devices (e.g., smartphones, iPad and tablets) raise student engagement in both indoor and outdoor activities with applications such as mobile augmented reality. New motion sensors and image-recognition technologies are giving rise to applications with more natural interaction methods, helping non-technical users to interact with computer-based systems, as in the case of new-generation video consoles. In addition, social networks and web 2.0 tools give students a more active role in their own education, allowing them to become educational "prosumers" (i.e., both producers and consumers). Especially integration of management information system and teaching and learning method based on MICT improved R\&T achievements substantially.

\section{A. MICT Benefit Both Teaching and Research Works}

Most evidence points out that there are too many advantages both in teaching and scientific research by applying modern information technology and communication methods in today's university.

On one hand, MICT makes the course interesting and diversifies, and lets the scientific research visually. After comparison of computer aided education vs. traditional education. Cingi thought that computer aided education (CAE) system is a key to improve the effectiveness and the quality of education system. Computer education forms a part of the school and college curricula, as it is important for every individual today [4]. The developments in communications and wireless technologies of mobile devices have prompted educators and researchers to take a pedagogical view toward developing educational applications for mobile devices to promote teaching and learning, and research on mobile learning has expanded significantly [5]. Abilkhamitkyzy argued that actually computer aided education and research eases the process of learning and studies. In educational process the wide usage of computers and informational technologies led to interactive formation of education [6]. The computer assisted learning program has a robust and consistently positive impact on student academic performance. The drills and exercise provided by the software of computer assisted learning program, the freshness of the novel technology and the prompt interaction and immediate feedback from computers may have all contributed to the positive impact in student learning [7]. According to Wang, teachers and students to cooperate in scientific research can increase student's learning interest, create equality atmosphere between student and teacher, and cultivate innovation capability both student and teacher [8]. Elliot believed that because science is both theoretical and practical, the usefulness of ICT and multimedia will be in both the "thinking" and "practical" aspects of science. Not only does multimedia help address the challenges in science lessons, it also instils a sense of wonder in pupils resulting in improved motivation and better real-life connections and helps overcome pupils' misperceptions of science, eg, its relevance being restricted to pupils wanting to pursue science-based professions [9].
After summarises on research on seeking to integrate ICT and digital tools in environmental education, Fauville calls for further studies that will provide models of productive forms of teaching and learning that harness ICT resources, particularly in developing the goals and methodologies of environmental education in the twenty-first century [10]. Even MICT has triggered profound changes in the military field. Information becomes the dominant factor for war. To promote information literacy, military harness MICT to reform information literacy training system, optimize information technology teaching environment, exercise capacity for scientific research, expand education and training channels [11].

On the other hand, the World Wide Web provided giant information resources for R\&T. Internet, which is the source of all sorts of information, plays an important role in education and research. As it is an enormous information base, it can serve as a source for a wide variety of subjects. Search engines such as Google are great helpful in reaching searcher's aim. It is usually possible to reach the headed information when the clues or keywords sometimes are obscure. This is another advantage of computers to thick textbooks, reference book even library. The emergence of the World Wide Web as a tool in research and discovery offers science education an opportunity to share information and perspectives which engage students with the scientific community. Students are able to access open, transparent sites creating common resources pools and autonomous working groups which can be used for shared problem solving. In addition, web-focused education can also help remake scientific product as a public good in the lives of both science researchers and science consumers [12]. Task-driven teaching model is applying to help students to use learning resources actively to carry out the study more effectively [13].

The culture of university campus network is a new form of civilization that has the characteristics of vivid form, abundant content and rapid actual effect. It's an important source of information on campus for teachers and students [14]. Web based proctoring can also be employed to counter deception and dishonesty in online exams [15].

\section{B. MICT Improve Managing Efficiency for R\&T Management}

Computer technology has already entered the modern education field and formed one new and developing boundary science. The use of computer management of teaching operation and realization of statistic and analysis of computer, it becomes an important measure to realize the scientific, standardization of teaching management, ever realizing information management teaching. It is needed to solve the problem how many teaching operation data quickly and meeting user requirements and statistical analysis of a set of help to optimize the teaching management data. Educational systems and resources proliferate nowadays, many institutions take advantage of advances in multimedia, networking and software engineering to offer training products and services at all levels.

The study route of teacher evaluation is basically along the reward and punishment evaluation, from developmental evaluation to the performance evaluation. After comparing 
with foreign study, Wang argued that the Chinese studies are relatively backward, whether in theory or in practice [16]. Based on the study of teaching management work at the same time, combining the theory of data mining, Jiang explores a suitable statistic and analysis of algorithm teaching management data of the problem [17].

\section{MICT Create New R\&T Management Style}

Education is a complex process in which both human and technical resources should be utilized in a carefully balanced way. Traditional teaching practice, learning methods and course content have all been affected by the introduction of computer technology. The challenge is to develop and use modern learning environments in education while the curriculum of university education is continuously evaluated and modified to both include new ideas, thinking and learning methods, and to eliminate redundant material.

Campus network is an important source of information on campus for teachers and students, and it plays an active role in publicity and education guidance [17]. Empirical research shows that a positive attitude towards ICT facilitates their integration in education [18].

\section{RUT Prompts Joint Growing for R\&T}

RUT mechanism can benefit to coagulation of scientific research direction, sufficient scientific research funds, abundant scientific research achievements, dense academic atmosphere and so on.

On one hand, faculties could integrate their research into teaching and deliver the newest research achievement to student. On another hand, the students could improve their abilities of identifying, analysing and solving problems through participating in scientific research. Moreover, faculties also can carry out individuation teaching method and improve their abilities of management and research organization.

\section{Mutual REINFORCING PlatFORM FOR R\&T}

The leading role of research in collage is professor, and both teachers and students are participants in school teaching activities. The scientific research can enrich professor's knowledge and broaden their horizon, and make their class density and informative. What the students have learned in class also can be deepen while they are engaging in assistant research. The students' having a hand in assistant research can speed up the whole research process, improve professor's research standard and increase professor's scientific research abilities. Once such a mutual-growing-mechanism being formulated and grown, there will be a virtuous circle created among teaching and scientific research. Here we deliberate the details of this mechanism.

\section{A. General Framework for Mutual Reinforcement Mechanism for $R \& T$ in University}

Fig. 1 shows a general framework for mutual reinforcement mechanism of teaching and scientific research in collage. There are two management information system platforms to manage collage's teaching and research--Teaching Affairs
Management System and Scientific Research Management System. Professors engage in both teaching and scientific research works and students take part in parts of scientific research work and all teaching affairs. Both the Teaching Affairs Management System and Scientific Research Management System share the same data for the convenience of professors and students' assessment, and also for teaching and research assessment.

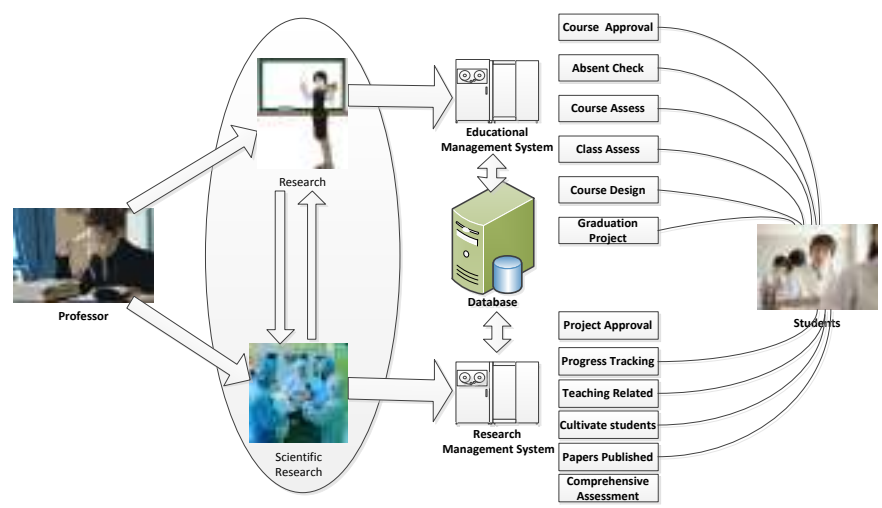

Fig. 1 General framework for mutual reinforcement mechanism of teaching and scientific research in collage

Construct assessment rank mechanism both for teachers and students. Fig. 2 shows the rank level for both students and teachers in courses. The teachers and students get his rank according to mutual s appraisement. The rank is the important aspect of appraisement for student and teacher's reputation.

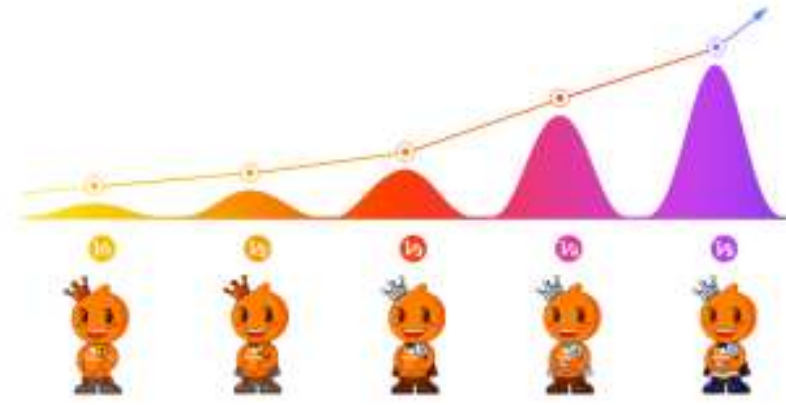

Fig. 2 Rank level for students and teachers reputation

\section{B. Assessment for Proposing a New Course}

According to his research program, professor proposes his course target, course outline and courseware. The academic committee of his research group assesses the course's quality and decides whether the course should be set up. Once the course was decided to be given, the course's outline, textbook, and courseware etc. are posted on the website of the Teaching Affairs Management System. Student can select this course in the management system.

The original textbook especially written in English is encouraged to be selected, and also set the hortative mechanism for teachers to compiled textbook themselves.

If number of the student selecting this course less than a certain number, the course will be stop. The total number of students selecting this course will be taken as criteria to access professor R\&T work. 


\section{Assessment Mechanism for Courses}

In order to show some foundation for students to select certain course, course assessment mechanism must be built up. Here a five-grade marking assessment mechanism is introduced to professor's course appraisement. Every student involved in class will be demanded to give his teacher a score for his joined class.

1) Course Appraisement of Students: Using the Teaching Affairs Management System, every student gives course's attitude marks according to professor's performance for every course with the five-grade marking system.

2) Weights for Student's Appraisement: In order to avoid malicious appraisement both for students and teachers, different student involved in class are assigned various weight for their appraisement according to their previous reputation professor have given him in class. The weight is determined by the total appraisement that all teacher haven given him of his previous classes. Professor appraise student according to student's work in class, homework and their midterm/final examination scores.

3) Course Rank Mechanism: According to the scores that student have appraised for professor's course, a total marks for one subject is applied to decide the course's rank.

4) Decoupling examination from teaching To Carry on objective appraisal to teaching effects, standard examination database should be adopted. The mechanism decoupled examination from teaching should be a fair way to evaluate professor's teaching output.

\section{Assessment for Student's Learning Effect}

The student is the main body of teaching affairs, and what the students have learned in class or in school should be critical metrics for assessment for classes.

1) Student Present Class Checking: To ensure the quality of teaching, better rates of class attendance is most important policy for teaching. QR code Scanning is used to check student's present for class. Fig 3 shows the framework for checking student absent class by using student scanning QR code in class.

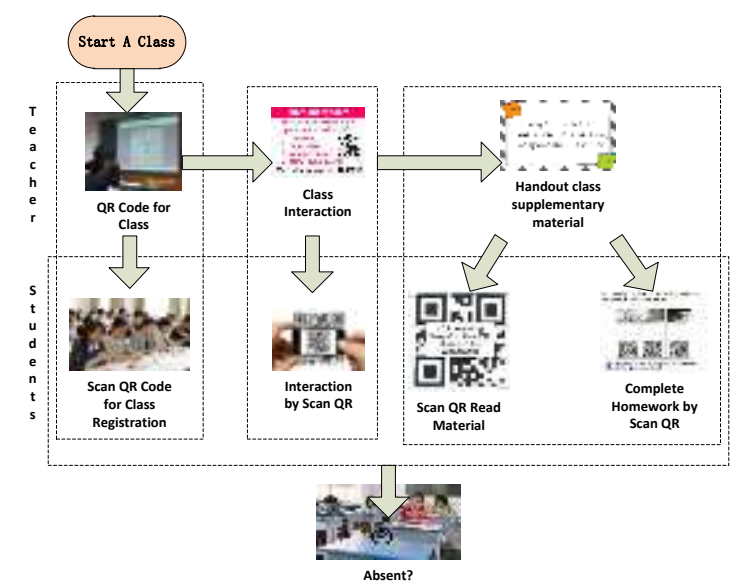

Fig. 3 A framework students absent class checking by scanning QR code
2) New Methods for Enhancing Classroom Interaction: The degree of student involved in the classroom interaction also should be most important aspect for student's appraisement. Traditionally, Classroom interaction refers to the oral interaction that occurs between teachers and students among students. Nowadays, there are lot of modern methods can be used in class interaction, such as mobile or iPad and it can make the class interesting and lively.

3) Research Work and Social Activities Involvement for Student Appraisement: Research assistant works can improve student's scientific research ability directly and having a hand in society activities can train student's problem solving ability. Appraisement factors in these issues should include:

- Number of patents or software copyright applied,

- Number of paper published,

- Certification, award or medal.

Compressive assessment for Student's learning effect should also include traditional issues such as homework, classwork, test and examination etc.

\section{E. Mutual Constrain Assessment for Teachers and Students}

As it was well known that Taobao assessment mechanism is mutual constrain assessment method both for sales and customs and it is comprehensive appraisement architecture. Here the Taobao assessment mechanism is applied to guarantee fairness of the appraisement for both students and teachers.

Every student must be accepted appraisement given by the teacher that have given the course according to the student's behavior and every teacher have to receive the appraisement form the student involved in his class. The appraisement both for student and teacher is essential part of the whole teaching affairs. According to their mutual appraisement the teacher and student reputation rank is resolves in the Teaching Affairs Management System.

The weight of appraisement for student and teacher also depend on their teaching/learning reputation rank. The teaching/learning reputation rank also are important index for teacher' teaching and student's learning effects.

\section{F. To Form an Organization of Institute Being Entity But Department Being Dummy}

In order to improve scientific research level and teaching quality, qualified person must be cultivated and introduced. New style R\&T organization based on academic team and principal investigators should be formed for purpose of benefits both research and teaching. The academic team is an academic research unit or entity that the academic leader is the core of that, and it may be made from a number of teachers and technical staff in laboratory. Every team's research topic should correspond to one of the department's planning directions of subject, even several academic teams for particularly important or extensive research scope.

The policies and resources are definitely more skewed towards academic team that they are better developed or good achievements. The authority can manage academic scope human resource and administration for academic team 
dynamically, and help them making decision on team's configuration, assessment and dismiss of related basis rules.

According to staff's special skills the academic team arrange teacher's courses to improve teaching quality. If the assessment for a certain course is not as good enough sometimes even bad, there will be fewer students to select this course. On the other hand this will make a promotion for excellent teacher to give teaching.

\section{G. Comprehensive Evaluation for Professors' Achievements}

The goal for collage is to strive a joint growing of scientific research and teaching. Therefore to assess teacher's achievement should depend on their research and teaching works. A comprehensive assessment should include various aspects both in scientific research and teaching works, such as project's incomes, project related course and involved students etc. Several aspects for a general appraisement are as shown in Table I.

TABLE I

GENERAL APPRAISEMENT RULES For PROFESSOR

\begin{tabular}{|c|c|c|c|}
\hline \multirow{2}{*}{ No. } & \multicolumn{3}{|c|}{ Items, rank and weight } \\
\hline & Items & Rank & Weights(\%) \\
\hline 1 & Contract Amount & 1 & 1 \\
\hline 2 & Actual Incomes & I & 30 \\
\hline 3 & Num. of Student Involved & I & 1 \\
\hline 4 & Num. of Teacher Involved & 1 & 5 \\
\hline 5 & Num. of Student cultivated & I & 2 \\
\hline 6 & Software Copyright Applied & I & 2 \\
\hline 7 & Patents Applied & I & 3 \\
\hline 8 & \multirow{3}{*}{ Num. of Paper Published } & 1 & 5 \\
\hline 9 & & 2 & 4 \\
\hline 10 & & 3 & 3 \\
\hline 11 & \multirow{2}{*}{$\begin{array}{l}\text { Certification, Award and } \\
\text { Medal }\end{array}$} & 1 & 5 \\
\hline 12 & & 2 & 4 \\
\hline 13 & \multirow{2}{*}{$\begin{array}{l}\text { General Marks Assessed by } \\
\text { Student }\end{array}$} & 1 & 3 \\
\hline 14 & & 2 & 3 \\
\hline$\cdots$ & & & \\
\hline Tota & & & \\
\hline
\end{tabular}

\section{CONCLUSIONS}

Research is the fountainhead of innovation for teaching. The collage's policy should strengthen more on scientific research in collage's R\&T affairs. The teacher should be encouraged to engage scientific research more than teaching. Collage's vitality lies in innovation. Hence energetic assessment mechanism and academic environment benefit for both research and teaching should be built up. With scientific RUT and with teaching prompt research should be pay more attention in improving collage's teaching standard.

The developed modern MICT technology provided critical method for managing teaching and research affairs in collage. By using the advanced platform and appreciate management mechanism, A prosperity for both scientific research and teaching will be never seen before appeared in collage yard. Therefore, R\&T type of university not only should encourage policies of laying equal stress on scientific research and teaching, but also have to take measures to coordinate them effectively.

\section{ACKNOWLEDGMENT}

This work is supported by 973 Program of China under Grant No. 2011CB711000, Zhejiang Provincial Natural Science Foundation under Grant No. LY12C09005, Y1110477, National Natural Science Foundation of China under Grant No.61100183 and Zhejiang Provincial Commonweal Technical Project under Grant No.2013C33063.We gratefully appreciate this support.

\section{REFERENCES}

[1] Xiaoyan Zhang, and Peng Nan. The Conception and Practice of Research-Based Teaching in Research Universities. 2014 International Conference on Education Reform and Modern Management (ERMM14)[Internet]. Atlantis Press. 2014.

[2] Xuan Ma, Construction of management mechanism on strengthening of both teaching and scientific research in university. Chinese University Science \& Technology 9 (2015): 011

[3] Martin, Sergio, et al. New technology trends in education: Seven years of forecasts and convergence. Computers \& Education 57.3 (2011) 1893-1906.

[4] Cingi, Can Cemal. Computer Aided Education. Procedia-Social and Behavioral Sciences 103 (2013): 220-229.

[5] Wu, Wen-Hsiung, et al. Review of trends from mobile learning studies: A meta-analysis. Computers \& Education 59.2 (2012): 817-827.

[6] Abilkhamitkyzy, R., Zh A. Aimukhambet, and K. K. Sarekenova. Organization of Independent Work of Students on Credit Technology. Procedia-Social and Behavioral Sciences 143 (2014): 274-278.

[7] Mo, Di, et al. Computer technology in education: Evidence from a pooled study of computer assisted learning programs among rural students in China. China Economic Review 36 (2015): 131-145.

[8] Yuanqiang Wang, The Training Strategies of Inquiry Learning Behavior for Students in Scientific Research Team Cooperated with Teachers and Students, International Conference On Complex Science Management and Education Science (CSMES 2013).2013, 500-504.

[9] Elliot, Dely, Delia Wilson, and Stephen Boyle. Science learning via multimedia portal resources: The Scottish case. British Journal of Educational Technology 45.4 (2014): 571-580.

[10] Fauville, Geraldine, Annika Lantz-Andersson, and Roger Säljö. ICT tools in environmental education: reviewing two newcomers to schools. Environmental Education Research 20.2 (2014): 248-283.

[11] Yanmei Wu, Zhijun Peng, and Xingwang Wen. Reformation Professional academies Information literacy Education Promotion High-quality Information Military Talent Training. 2013 the International Conference on Education Technology and Information System (ICETIS 2013). Atlantis Press, 2013.

[12] Karno, Donna, and Michael Glassman. Science as a Web of Trails: Redesigning Science Education with the Tools of the Present to Meet the Needs of the Future. Journal of Science Education and Technology 22.6 (2013): 927-933.

[13] Lanzhen Chen, Rudan Lin, and Xiaopeng Li. Discussion on the classroom teaching model of task-driven and education combined with research in Computer programming courses. (2015).

[14] Yu Gong. Construction based on the social development needs of the university network platform. 2014 International Conference on Computer Science and Electronic Technology (ICCSET 2014). Atlantis Press, 2015.

[15] Hylton, Kenrie, Yair Levy, and Laurie P. Dringus. Utilizing webcambased proctoring to deter misconduct in online exams. Computers \& Education 92 (2016): 53-63.

[16] Jiayi, Wang, and Cheng Ling. Reviewing teacher evaluation of rewards and punishments: the overview of Chinese teacher evaluation research. Education Research International 2012 (2012).

[17] Jinglan Jiang, Research and Application of Data Mining Technology in Teaching Management. 2013 3RD international conference on education and education management (eem 2013),2013, Vo1 25. 174179.

[18] Hernández-Ramos, J. Pablo, et al. Teachers' attitude regarding the use of ICT. A factor reliability and validity study. Computers in Human Behavior 31 (2014): 509-516. 